\title{
Parallel Adaptation of the Rabbit Renal Cortical Sodium/Proton Antiporter and Sodium/Bicarbonate Cotransporter in Metabolic Acidosis and Alkalosis
}

Takashi Akiba, Vito K. Rocco, and David G. Wamock

Nephrology Section, Veterans Administration Medical Center, San Francisco, California 94121; and Cardiovascular Research Institute and Department of Medicine and Pharmacology, University of California, San Francisco, California 94143

\begin{abstract}
Recent studies have shown that the bicarbonate reabsorptive capacity of the proximal tubule is increased in metabolic acidosis. For net bicarbonate reabsorption to be regulated, there may be changes in the rate of apical $\mathbf{H}^{+}$secretion as well as in the basolateral base exit step. The present studies examined the rate of $\mathrm{Na}^{+} / \mathrm{H}^{+}$exchange (acridine orange method) and $\mathrm{Na}^{+} / \mathrm{HCO}_{3}$ cotransport ( ${ }^{22} \mathrm{Na}$ uptake) in apical and basolateral membranes prepared from the rabbit renal cortex by sucrose density gradient centrifugation. $\mathrm{NH}_{4} \mathrm{Cl}$ loading was used to produce acidosis (arterial pH, 7.27 \pm 0.03 ), and Cl-deficient diet with furosemide was used to produce alkalosis (arterial $\mathrm{pH}, 7.51 \pm 0.02$ ). Maximal transport rate $\left(V_{\max }\right)$ of $\mathrm{Na}^{+} / \mathrm{H}^{+}$antiporter and $\mathrm{Na}^{+} / \mathrm{HCO}_{3}$ cotransporter were inversely related with plasma bicarbonate concentration from 6 to $39 \mathrm{mM}$. Furthermore, the maximal transport rates of both systems varied in parallel; when $V_{\max }$ for the $\mathrm{Na}^{+}$/ $\mathrm{HCO}_{3}$ cotransporter was plotted against $V_{\max }$ for the $\mathrm{Na}^{+} / \mathrm{H}^{+}$ antiporter for each of the 24 groups of rabbits, the regression coefficient $(r)$ was $0.648(P<0.001)$. There was no effect of acidosis or alkalosis on affinity for $\mathrm{Na}^{+}$of either transporter. We conclude that both apical and basolateral $\mathrm{H}^{+} / \mathrm{HCO}_{3}$ transporters adapt during acid-base disturbances, and that the maximal transport rates of both systems vary in parallel during such acid-base perturbations.
\end{abstract}

\section{Introduction}

Reabsorption of water and solute by the renal proximal tubule is a dynamic process that can adapt to several changing physiologic factors: glomerular filtration rate, state of acid-base and electrolyte balance, and different hormones. The $\mathrm{Na}^{+} / \mathrm{H}^{+}$antiporter of the brush border membrane of proximal tubules shows adaptive changes in the maximal rate of transport $\left(V_{\max }\right)$ in metabolic acidosis (1-3) and metabolic alkalosis (4). Other factors, including parathyroidectomy, glucocorticoid administration, unilateral nephrectomy, potassium depletion, and renal ablation also increase the $V_{\max }$ of the brush border $\mathrm{Na}^{+} / \mathrm{H}^{+}$antiporter $(1,5-8)$. Recently a sodium/bicarbonate cotransporter has been described in basolateral membrane vesicles prepared from rabbit renal cortex $(9,10)$. This transporter plays a significant role in bicarbonate reabsorption and regulation of intracellular $\mathrm{pH}$ in

Portions of these results have been reported in abstract form (1987. Kidney Int. 31:404).

Address correspondence and reprint requests to D. G. Warnock, M.D., Department of Medicine (111J), Veterans Administration Medical Center, 4150 Clement Street, San Francisco, CA 94121.

Received for publication 8 September 1986 and in revised form 23 March 1987.

The Journal of Clinical Investigation, Inc.

Volume 80, August 1987, 308-315 the proximal tubular cell (11-19). The factors that regulate the activity of this transporter have not yet been identified.

Recent work has established that systemic $\mathrm{pH}$, and therefore peritubular $\mathrm{pH}$, plays a central role in the regulation of bicarbonate reabsorption in the proximal tubule $(20,21)$. Indeed, the intrinsic reabsorptive capacity for bicarbonate of the proximal tubule is increased in chronic respiratory (22) and metabolic acidosis (23), and decreased in chronic metabolic alkalosis (24). Because bicarbonate reabsorption represents a vectorial process by which $\mathrm{H}^{+}$is secreted across the brush border membrane and base equivalents are transported across the basolateral membrane, these findings raise the possibility that the activity of the bicarbonate reabsorptive processes in both membranes may be adaptively regulated during states of chronic acid-base disturbance.

Renal proximal cells in rats with chronic metabolic acidosis show significant reductions in intracellular $\mathrm{pH}$, as estimated by weak acid accumulation (25), ${ }^{31} \mathrm{P}$ nuclear magnetic resonance (26), and the contents of citrate and alpha-ketoglutarate (27). Such a fall in intracellular $\mathrm{pH}$ might stimulate $\mathrm{H}^{+}$secretion across the brush border membrane by activation of the $\mathrm{Na}^{+} / \mathrm{H}^{+}$antiporter (28). If the base exit step across the basolateral membrane is also stimulated in acidosis, then the intracellular $\mathrm{pH}$ of proximal tubular cells would remain low as a consequence of the parallel changes in the mechanisms of $\mathrm{H}^{+}$transport across the brush border membrane (e.g., $\mathrm{Na}^{+} / \mathrm{H}^{+}$antiporter), and base exit across the basolateral membrane.

The present studies examined the possibility that adaptive changes of these transporters occur in response to acid-base disturbances. The results of our present studies indicate that $V_{\max } \mathrm{s}$ of $\mathrm{Na}^{+} / \mathrm{H}^{+}$antiporter and $\mathrm{Na}^{+} / \mathrm{HCO}_{3}$ cotransporter adapted in parallel to metabolic alkalosis and acidosis, without significant changes in Michaelis constants $\left(K_{\mathrm{m}}\right)$ for sodium. This adaptive response to acid-base disturbances would maintain intracellular $\mathrm{pH}$ in a relatively narrow range when the rate of transcellular bicarbonate absorption is changed by metabolic acidosis or alkalosis.

\section{Methods}

Experimental models were devised to study metabolic alkalosis and acidosis of relatively short duration, e.g., 24-48 h. A paired design was utilized because control rabbits can display a fairly wide range of systemic $\mathrm{pH}$ (2). In every instance, a group of experimental and control animals, obtained in the same shipment from a single vendor, were studied at the same time. Female New Zealand white rabbits, weighing $1.7-3.0 \mathrm{~kg}$, were used in these studies.

Arterial blood was obtained with a heparinized syringe from the medial ear artery and kept on ice until analyzed with an ABL 1 Acid-Base Laboratory (Radiometer A/S, Copenhagen, Denmark). The rest of the plasma sample was used to measure sodium, potassium, chloride, urea nitrogen, and creatinine concentrations by standard methods.

Metabolic alkalosis model. Four to six rabbits in each experiment 
were fed a bicarbonate-containing, chloride-deficient diet (Teklad Diet, Madison, WI). The control rabbits received standard regular rabbit chow. Both groups were fed $24 \mathrm{~g}$ of chow via gastric tube twice daily for $2 \mathrm{~d}$. It was necessary to gavage the animals because the experimental animals would not eat the chloride-deficient diet on their own. The experimental diet contained $7.8 \%$ bicarbonate, $<0.05 \%$ elemental chloride, and 3.42 $\mathrm{kcal} / \mathrm{g}$. The experimental rabbits also received $40 \mathrm{mg}$ furosemide i.m. once or twice a day for both days that the diet was administered (4). The control rabbits received a similar volume of normal saline intramuscularly. Both groups were allowed free access to water. Arterial blood gas analysis was done on the third morning and appropriate rabbits were selected for sacrifice and membrane vesicle preparation.

Metabolic acidosis model. Food was removed from a group of four rabbits in the morning, and they were gavaged with $35 \mathrm{ml}$ of $0.5 \mathrm{M}$ ammonium chloride that morning and in the afternoon. They were allowed to drink water ad lib. but were not fed during the acidosis period. The control rabbits were gavaged with $35 \mathrm{ml}$ of $0.5 \mathrm{M}$ ammonium bicarbonate in the morning and evening, and were allowed free access to regular rabbit chow and water. Arterial blood gas analysis was done the next morning, and appropriate rabbits were selected for sacrifice and membrane vesicle preparation.

Membrane preparation. Basolateral membrane vesicles and brush border membrane vesicles from the renal cortices were prepared by the method reported by Ives et al. (29). Although the marker enzyme enrichment for the brush border membranes is not as high as with the traditional magnesium-aggregation technique, this approach was chosen because both basolateral and brush border membranes could be prepared simultaneously and harvested from the same sucrose density gradients. In brief, two or three rabbits of the alkalosis group and their controls or the acidosis group and their controls were decapitated, and their kidneys were flushed via the renal arteries with $30 \mathrm{ml}$ of ice-cold homogenizing solution (50 mM sucrose; $10 \mathrm{mM}$ Hepes/Tris, $\mathrm{pH} 7.5 ; 5 \mathrm{mM}$ EGTA/ Tris, $\mathrm{pH}$ 7.5). The cortices were then homogenized in $300 \mathrm{ml}$ of the same buffer with a Sorvall Omnimixer (Omni Instruments, Newton, CT) at full speed for $4 \mathrm{~min}$. The homogenate was centrifuged for $15 \mathrm{~min}$ at 4,500 rpm in the JA-20 rotor of a J2-21 centrifuge (Beckman Instruments, Inc., Fullerton, CA), $(2,450 \mathrm{~g})$. The supernatants were centrifuged at $17,000 \mathrm{rpm}$ for $30 \mathrm{~min}(35,000 \mathrm{~g})$. The pellets were suspended in the buffer by passage through a 22 -gauge needle and centrifuged at 20,000 $\mathrm{rpm}$ for $60 \mathrm{~min}(48,400 \mathrm{~g})$. The fluffy upper layer of this pellet was washed with $\sim 20 \mathrm{ml}$ of isotonic buffer ( $250 \mathrm{mM}$ sucrose; $10 \mathrm{mM}$ Hepes/ Tris, pH 7.5) and centrifuged at $20,000 \mathrm{rpm}$ for $60 \mathrm{~min}$. The fluffy layer of this final pellet $\left(\mathbf{P}_{3}\right.$-light) was bottom loaded under sucrose density gradients as detailed below.

Sucrose density centrifugation. $35 \mathrm{ml}$ linear $35-48 \%$ (wt/vol) sucrose density gradients containing $10 \mathrm{mM}$ Hepes/Tris, $\mathrm{pH} 7.5$, were used. The final pellets $\left(\mathrm{P}_{3}\right.$-light) were mixed with $72 \%$ sucrose $(1: 2)$, bottom loaded under sucrose gradients, and centrifuged overnight at 27,000 rpm in a SW-28 rotor $\left(g_{\text {avg }}=100,000\right)$ and an L8-70M ultracentrifuge (Beckman Instruments, Inc.). The gradients were aliquoted into 3-ml fractions with a Buchler Auto Densi-Flow II (Haake-Buchler Instruments, Fort Lee, $\mathrm{NJ}$ ), and similar fractions from parallel gradients were pooled together. Maltase and $\mathrm{Na}^{+} / \mathrm{K}^{+}$-dependent ATPase activities of each fraction were measured. The two or three fractions with the highest maltase activity and the highest activity of $\mathrm{Na}^{+} / \mathrm{K}^{+}$-dependent ATPase were chosen as brush border membrane vesicles and basolateral membrane vesicles, respectively. The pooled fractions were washed with $10 \mathrm{mM}$ Hepes/Tris, $\mathrm{pH} 7.5$, and stored at $-70^{\circ} \mathrm{C}$ until transport assays were undertaken.

Enzyme assays. Maltase activity was determined by measuring the release of glucose from maltose with the hexokinase reaction (30). $\mathrm{Na}^{+}$/ $\mathrm{K}^{+}$-dependent ATPase activity was assayed with the coupled assay of Schoner et al. (31). Protein concentration was determined using the method of Lowry et al. (32).

$\mathrm{Na}^{+} / \mathrm{H}^{+}$antiporter assays. $\mathrm{Na}^{+} / \mathrm{H}^{+}$exchange rates were determined using the fluorescence quenching of acridine orange as previously described (33). The brush border membrane vesicles were preloaded with ice-cold buffer ( $250 \mathrm{mM}$ sucrose; $10 \mathrm{mM}$ Hepes/Tris, $\mathrm{pH} \mathrm{6.0)}$ ) and adjusted to a protein concentration of $15-25 \mathrm{mg} / \mathrm{ml}$. The fluorescence of acridine orange (excitation, $493 \mathrm{~nm}$; emission, $530 \mathrm{~nm}$ ) was measured in a thermoregulated ratio spectrofluorometer. The assay solution consisted of $6 \mu \mathrm{M}$ acridine orange, $250 \mathrm{mM}$ sucrose, $10 \mathrm{mM}$ Hepes/Tris at pH 7.5 and $150 \mathrm{mM} N$-methylglucamine gluconate. $\mathrm{Na}^{+} / \mathrm{H}^{+}$exchange rates were determined in triplicate by the rate of the recovery of fluorescence after addition of sodium gluconate giving final sodium concentrations of $90,50,25,10$, and $5 \mathrm{mM}$. Eadie-Hofstee analysis (34) was used to obtain values for $V_{\max }$ and $K_{\mathrm{m}}$. Amiloride inhibition was determined using $100 \mu \mathrm{M}$ amiloride and $90 \mathrm{mM}$ sodium in the external buffer and was uniformly found to be similar in all groups: control acidosis, $43.6 \pm 6.3 \%$ inhibition; acidosis, $43.5 \pm 2.4 \%$ inhibition; control alkalosis, $39.4 \pm 1.6 \%$ inhibition; and alkalosis, $40.3 \pm 5.1 \%$ inhibition.

$\mathrm{Na}^{+} / \mathrm{HCO}_{3}$ cotransporter assays. $\mathrm{Na}^{+} / \mathrm{HCO}_{3}$ cotransport rates were measured by isotopic sodium uptake (9). Briefly, ${ }^{22} \mathrm{Na}$ uptake was measured at $25^{\circ} \mathrm{C}$ by a rapid filtration technique. The basolateral membrane vesicles were preloaded with $200 \mathrm{mM}$ sucrose, $50 \mathrm{mM}$ Hepes/Tris, $\mathrm{pH}$ 7.5 , and $1 \mathrm{mM}$ magnesium chloride. The uptake was initiated by vortexing $5 \mu \mathrm{l}$ of membrane suspension in $25 \mu \mathrm{l}$ of uptake media. The final sodium concentrations were varied between 4.2 and $42 \mathrm{mM}$, and triplicate determinations were made at each so that Eadie-Hofstee analysis could be used to obtain values for $V_{\max }$ and $K_{\mathrm{m}}$. The 2-s uptake period was terminated by rapid mixture of $30 \mu \mathrm{l}$ of incubation mixture with $1.5 \mathrm{ml}$ of ice-cold stop solution ( $200 \mathrm{mM}$ sucrose, $50 \mathrm{mM}$ Hepes/Tris, $\mathrm{pH} 7.5$, $40 \mathrm{mM}$ potassium sulfate), the mixture rapidly transferred to a prewetted $0.45 \mu \mathrm{m}$ filter (Millipore/Continental Water Systems, Bedford, MA), and washed with an additional $3 \mathrm{ml}$ of ice-cold stop solution. Filters were counted by scintillation spectroscopy. Differences between ${ }^{22} \mathrm{Na}$ uptake in the presence of $21 \mathrm{mM}$ bicarbonate compared with gluconate were used as the activity of the $\mathrm{Na}^{+} / \mathrm{HCO}_{3}$ cotransporter (9).

Statistics. Kinetic parameters were obtained by linear regression analyses of Eadie-Hofstee plots. A total of six sets of animals were studied in the alkalosis model, and six sets in the acidosis model. Experimental animals and control animals were included in each set. The treatment of the animals in each paired control and experimental set of rabbits was as similar as possible. Rabbits from the same shipment were used for each set. Vesicle preparation and transport assays were done simultaneously for each set so that paired statistical analyses could be used to analyze the results. Statistical significance of the differences in the paired studies was estimated by paired $t$ test between the control and experimental results in each set. Results are expressed as mean \pm SEM.

\section{Results}

Dietary manipulation and/or diuretics significantly influenced the $\mathrm{pH}$ and bicarbonate concentration of arterial blood in acidotic and alkalotic groups (Table I). In the acidotic series, arterial blood $\mathrm{pH}$ was $7.27 \pm 0.03$ in the experimental group and $7.41 \pm 0.02$ in the control group for this series. In the alkalotic series, arterial blood pH was $7.51 \pm 0.02$ in the treated group and $7.39 \pm 0.02$ in the controls. Blood bicarbonate concentrations in the acidotic series were $9.7 \pm 1.1 \mathrm{mM}$ and $22.0 \pm 0.7 \mathrm{mM}$ in their controls. Blood bicarbonate concentrations in the alkalotic series were $32.7 \pm 1.5 \mathrm{mM}$ in the alkalotic group and $21.6 \pm 1.3 \mathrm{mM}$ in their controls. The different sham treatments of both control groups did not induce any differences in their measured blood chemistries (Table I; nonpaired $t$ tests). Acidotic rabbits had significant hypocapnia and hyperchloremia. Alkalotic rabbits had significant hyponatremia, hypochloremia, and hypokalemia. There were significant increases in the blood urea nitrogen levels in the alkalotic and acidotic groups compared with their controls, but the changes in the serum creatinine concentrations did not reach statistical significance. These results suggest that both models of acid-base change were associated with volume depletion.

The enrichments of maltase activity in the brush border 
Table I. Principal Blood Parameters in Acidosis and Alkalosis

\begin{tabular}{|c|c|c|c|c|c|c|c|c|}
\hline & pH & $\mathrm{PCO}_{2}$ & $\mathrm{HCO}_{3}$ & $\mathrm{Cl}^{-}$ & $\mathrm{Na}^{+}$ & $\mathbf{K}^{+}$ & BUN & Creatinine \\
\hline & $U$ & torr & $m M$ & $m M$ & $m M$ & $m M$ & $m g / d l$ & $m g / d l$ \\
\hline \multicolumn{9}{|l|}{ Acidosis series } \\
\hline Control & $7.41 \pm 0.02$ & $34.8 \pm 0.6$ & $22.0 \pm 0.7$ & $102.8 \pm 0.5$ & $141.0 \pm 0.8$ & $4.6 \pm 0.3$ & $15.3 \pm 0.8$ & $0.82 \pm 0.11$ \\
\hline Acidosis & $7.27 \pm 0.03$ & $22.3 \pm 2.5$ & $9.7 \pm 1.1$ & $112.9 \pm 2.2$ & $141.9 \pm 1.5$ & $4.2 \pm 0.1$ & $21.2 \pm 1.3$ & $0.85 \pm 0.06$ \\
\hline Mean paired delta & $-0.15 \pm 0.03^{*}$ & $-12.5 \pm 2.4^{*}$ & $-12.3 \pm 1.3^{*}$ & $10.2 \pm 1.9^{*}$ & $0.9 \pm 1.5$ & $-0.4 \pm 0.2$ & $6.3 \pm 2.0^{\ddagger}$ & $0.03 \pm 0.11$ \\
\hline \multicolumn{9}{|l|}{ Alkalosis series } \\
\hline Control & $7.39 \pm 0.02$ & $35.8 \pm 2.2$ & $21.6 \pm 1.3$ & $103.2 \pm 1.1$ & $141.6 \pm 1.1$ & $5.0 \pm 0.3$ & $12.5 \pm 1.4$ & $0.74 \pm 0.10$ \\
\hline Alkalosis & $7.51 \pm 0.02$ & $40.1 \pm 0.9$ & $32.7 \pm 1.5$ & $85.7 \pm 2.0$ & $132.4 \pm 1.2$ & $3.5 \pm 0.1$ & $34.8 \pm 4.4$ & $1.14 \pm 0.12$ \\
\hline Mean paired delta & $0.13 \pm 0.03^{8}$ & $4.3 \pm 2.5$ & $11.7 \pm 2.1^{*}$ & $-17.5 \pm 2.2^{*}$ & $-9.2 \pm 0.8^{*}$ & $-1.5 \pm 0.4^{8}$ & $22.3 \pm 3.8^{\ddagger}$ & $0.40 \pm 0.15$ \\
\hline
\end{tabular}

Mean \pm SEM. $n=6$ paired sets of rabbits in each series. ${ }^{*} P<0.005$. $^{\ddagger} P<0.05$ (Only five sets of values were obtained for BUN and creatinine.) $P<0.01$.

Table II. Marker Enzyme Analyses in Acidosis and Alkalosis

\begin{tabular}{|c|c|c|c|c|}
\hline & \multicolumn{2}{|c|}{ Brush border vesicle maltase } & \multicolumn{2}{|c|}{$\begin{array}{l}\text { Basolateral membrane } \\
\mathrm{Na}^{+} / \mathbf{K}^{+} \text {-dependent ATPase }\end{array}$} \\
\hline & SA & EF & SA & EF \\
\hline & $\mu \mathrm{mol} / \mathrm{mg} \cdot \min$ & $\mu \mathrm{mol} / \mathrm{mg} \cdot \min$ & $\mu \mathrm{mol} / \mathrm{mg} \cdot \min$ & $\mu \mathrm{mol} / \mathrm{mg} \cdot \mathrm{min}$ \\
\hline \multicolumn{5}{|l|}{ Acidosis series } \\
\hline Control & $41.6 \pm 1.4$ & $6.7 \pm 1.4$ & $1.43 \pm 0.29$ & $10.1 \pm 1.5$ \\
\hline Acidosis & $57.4 \pm 7.9$ & $7.7 \pm 1.4$ & $1.47 \pm 0.44$ & $8.3 \pm 1.0$ \\
\hline Mean paired delta & $-15.5 \pm 8.5$ & $-1.0 \pm 1.8$ & $-0.04 \pm 0.22$ & $1.8 \pm 1.5$ \\
\hline \multicolumn{5}{|l|}{ Alkalosis series } \\
\hline Control & $38.1 \pm 5.8$ & $6.6 \pm 1.4$ & $1.46 \pm 0.15$ & $8.2 \pm 1.9$ \\
\hline Alkalosis & $33.4 \pm 4.4$ & $5.8 \pm 0.9$ & $1.56 \pm 0.29$ & $6.3 \pm 0.9$ \\
\hline Mean paired delta & $4.7 \pm 5.7$ & $0.8 \pm 1.1$ & $-0.10 \pm 0.29$ & $1.9 \pm 1.4$ \\
\hline
\end{tabular}

Six sets of rabbits in each series. SA, specific activity; EF, enrichment factor.

membrane vesicle preparations compared with the homogenate activities were $7.7 \pm 1.4,6.7 \pm 1.4,5.8 \pm 0.9$, and $6.6 \pm 1.4$ in the acidosis group and their controls, and the alkalosis group and their controls, respectively. Enrichments of $\mathrm{Na}^{+}, \mathrm{K}^{+}$-dependent ATPase activities in the basolateral membrane preparations were $8.3 \pm 1.0,10.1 \pm 1.5,6.3 \pm 0.9$, and $8.2 \pm 1.9$ in the acidosis group and their controls, and in the alkalosis group and their controls, respectively. The specific activities and enrichment factors for both membrane markers were not significantly different by paired analysis among the various groups. These data are presented in Table II. In addition, the specific activities were also the same for both markers in the homogenates of all groups (data not shown). Furthermore, there were not any significant correlations between the enrichment factors for either enzyme and the blood bicarbonate concentrations for all of the 24 sets of experimental and control animals (data not shown).

Kinetic parameters of $\mathrm{H}^{+} / \mathrm{HCO}_{3}$ transporters are summarized in Table III. The $K_{m}$ values for sodium of the $\mathrm{Na}^{+} / \mathrm{H}^{+}$ antiporter of brush border membrane vesicles were not significantly different between acidosis, alkalosis, and their respective controls. In addition, all groups of brush border membranes demonstrated identical degrees of inhibition of $\mathrm{Na}^{+} / \mathrm{H}^{+}$antiporter activity when tested with $90 \mathrm{mM} \mathrm{Na}$ and $100 \mu \mathrm{M}$ amiloride (data not shown). In contrast, the $V_{\max }$ of the $\mathrm{Na}^{+} / \mathrm{H}^{+}$ antiporter was increased to $6.75 \pm 1.12$ arbitrary fluorescence units $(\mathrm{FU})^{1} / \mathrm{mg}$ protein $\cdot \mathrm{s}$ in acidosis compared with $3.95 \pm 0.94$ $\mathrm{FU} / \mathrm{mg}$ protein $\cdot \mathrm{s}$ in the simultaneous control group (mean paired difference, $2.81 \pm 0.33 \mathrm{FU} / \mathrm{mg}$ protein $\cdot \mathrm{s} ; P<0.001$ ). $V_{\max }$ of the $\mathrm{Na}^{+} / \mathrm{H}^{+}$antiporter in the alkalosis series was not significantly different from that of their controls (Table III). In addition, there were not any significant correlations between marker enzyme specific activities (Table II) and maximal transport rates for either the $\mathrm{Na} / \mathrm{H}$ antiporter or the $\mathrm{Na} / \mathrm{HCO}_{3}$ cotransporter (data not shown), ruling out the possibility that the changes in $V_{\max }$ were due to relative differences in amounts of brush border or basolateral membranes in the different preparations.

Similarly, the $K_{\mathrm{m}} \mathrm{s}$ for sodium of the $\mathrm{Na}^{+} / \mathrm{HCO}_{3}$ cotransporter in the acidosis and alkalosis groups were not significantly different from their controls. Furthermore, there were not any significant correlations between the $K_{\mathrm{m}} \mathrm{s}$ of either transport system and the blood bicarbonate concentrations for all of the 24 sets of experimental and control animals (data not shown). The $V_{\max }$ of the $\mathrm{Na}^{+} / \mathrm{HCO}_{3}$ cotransporter in the acidosis group was increased significantly to $3.56 \pm 0.55 \mathrm{nmol} / \mathrm{mg}$ protein $\cdot 2 \mathrm{~s}$ compared with $1.84 \pm 0.36 \mathrm{nmol} / \mathrm{mg}$ protein $\cdot 2 \mathrm{~s}$ in the vesicles from their control

1. Abbreviation used in this paper: FU, arbitrary fluorescence unit. 
Table III. Kinetic Parameters of $\mathrm{H}^{+}$Transport Systems in Acidosis and Alkalosis

\begin{tabular}{|c|c|c|c|c|}
\hline & \multicolumn{2}{|l|}{$\mathrm{Na}^{+} / \mathrm{H}^{+}$antiporter } & \multicolumn{2}{|c|}{$\mathrm{Na}^{+} / \mathrm{HCO}_{3}$ cotransporter } \\
\hline & $V_{\max }$ & $K_{\mathbf{m}}$ & $V_{\operatorname{mex}}$ & $K_{\mathrm{m}}$ \\
\hline & $F U / m g \cdot s$ & $m M$ & $n m o l / m g \cdot 2 s$ & $m M$ \\
\hline \multicolumn{5}{|l|}{ Acidosis series } \\
\hline Control & $3.95 \pm 0.94$ & $15.3 \pm 0.8$ & $1.84 \pm 0.36$ & $9.8 \pm 1.4$ \\
\hline Acidosis & $6.75 \pm 1.12$ & $23.6 \pm 4.6$ & $3.56 \pm 0.55$ & $14.3 \pm 2.9$ \\
\hline Mean paired delta & $2.81 \pm 0.33^{*}$ & $8.3 \pm 4.6$ & $1.71 \pm 0.51^{\ddagger}$ & $4.5 \pm 1.7$ \\
\hline \multicolumn{5}{|l|}{ Alkalosis series } \\
\hline Control & $5.21 \pm 1.09$ & $21.4 \pm 2.1$ & $2.07 \pm 0.19$ & $11.9 \pm 2.1$ \\
\hline Alkalosis & $3.55 \pm 0.74$ & $17.8 \pm 1.9$ & $1.14 \pm 0.18$ & $9.0 \pm 1.7$ \\
\hline Mean paired delta & $-1.66 \pm 0.73$ & $-3.6 \pm 1.9$ & $-0.93 \pm 0.26^{\ddagger}$ & $-2.9 \pm 3.3$ \\
\hline
\end{tabular}

Paired, two-tailed Student $t$ test. Six paired sets of rabbits in each series. ${ }^{*} P<0.001 .{ }^{\ddagger} P<0.025$.

rabbits (mean paired difference, $1.71 \pm 0.51 \mathrm{nmol} / \mathrm{mg}$ protein $\cdot 2$ s; $P<0.025$ ). Furthermore, $V_{\max }$ of the $\mathrm{Na}^{+} / \mathrm{HCO}_{3}$ cotransporter in the alkalosis group was decreased significantly to $1.14 \pm 0.18$ $\mathrm{nmol} / \mathrm{mg}$ protein $\cdot 2 \mathrm{~s}$ compared with $2.07 \pm 0.19 \mathrm{nmol} / \mathrm{mg}$ protein. $2 \mathrm{~s}$ in their control group (mean paired difference, $-0.93 \pm 0.26 \mathrm{nmol} / \mathrm{mg}$ protein $\cdot 2 \mathrm{~s} ; P<0.025$ ).

These data were plotted as a function of the blood bicarbonate concentration in Figs. 1 and 2. $V_{\max }$ of the $\mathrm{Na}^{+} / \mathrm{H}^{+}$ antiporter were significantly correlated with the blood bicarbonate concentration $(r=0.520 ; P<0.01$; d.f., 22), with a linear regression equation of $y=-0.15( \pm 0.05) x+8.17( \pm 2.25) . V_{\max }$ of the $\mathrm{Na}^{+} / \mathrm{HCO}_{3}$ cotransporter were also significantly correlated with blood bicarbonate concentration $(r=0.781 ; P<0.001$; d.f., 22), with a linear regression equation of $y=-0.11( \pm 0.02) x$ $+4.48( \pm 0.77)$

The data in Figs. 1 and 2 represent all 24 sets of determinations, but the paired responses in the alkalosis and acidosis groups are not apparent. Fig. 3 presents the paired comparisons of $\mathrm{Na}^{+} / \mathrm{HCO}_{3}$ cotransporter activity between the acidosis series

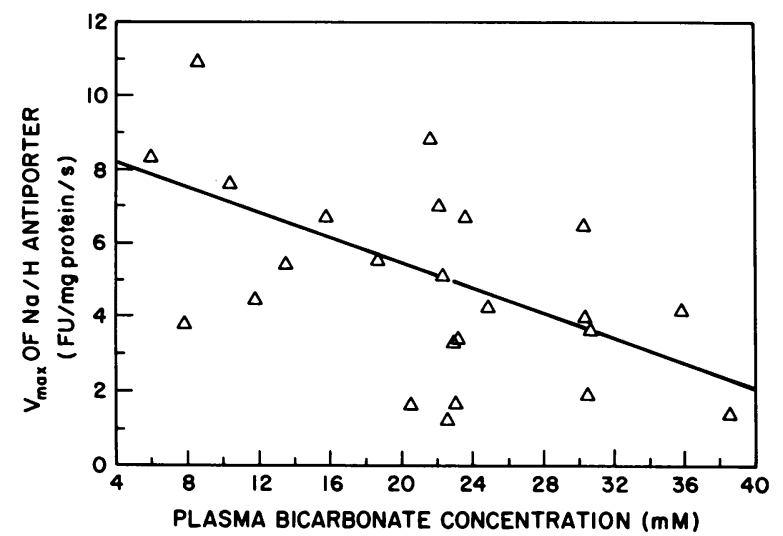

Figure 1. Relationship between blood bicarbonate concentration and maximal rate of $\mathrm{Na}^{+} / \mathrm{H}^{+}$antiporter. $V_{\max }(\mathrm{FU} / \mathrm{mg}$ protein $\cdot \mathrm{s}$ ) was determined by Eadie-Hofstee analysis of $\mathrm{Na}^{+} / \mathrm{H}^{+}$exchange rates in brush border vesicles. Each data point represents the value obtained from a single membrane preparation in a group of two or three rabbits. The bicarbonate concentration was obtained by arterial blood gas analysis and represents the mean value for rabbits in that group. The $V_{\max } \mathrm{s}$ of the $\mathrm{Na}^{+} / \mathrm{H}^{+}$antiporter were significantly correlated with blood bicarbonate concentration $(r=0.520 ; P<0.01 ;$ d.f., 22$)$, with a linear regression equation (solid line) of $y=-0.15( \pm 0.05) x+8.17( \pm 2.25)$. (squares) and the alkalosis series (circles). The open symbols for each series represent the concurrent controls, and the solid lines connect the appropriate control measurements with the experimental measurements made in the paired groups of rabbits. In every instance, there was an increase in the $V_{\max }$ of the $\mathrm{Na}^{+} /$ $\mathrm{HCO}_{3}$ cotransporter in acidosis compared with controls, and also a decrease in $V_{\max }$ in the alkalosis series. The average values and mean paired differences are presented in Table III.

Fig. 4 presents the paired comparisons of $\mathrm{Na}^{+} / \mathrm{H}^{+}$antiporter activity between the acidosis series (squares) and the alkalosis series (circles). The open symbols for each series represent the concurrent controls, and the solid lines connect the appropriate control measurements with the experimental measurements made in the paired set of rabbits. In every instance, there was an increase in $V_{\max }$ of the $\mathrm{Na}^{+} / \mathrm{H}^{+}$antiporter in acidosis compared with controls. The decrease in activity in the alkalosis series was not as striking. The average values and mean paired differences are presented in Table III.

Fig. 5 presents a comparison of the maximal transport rates

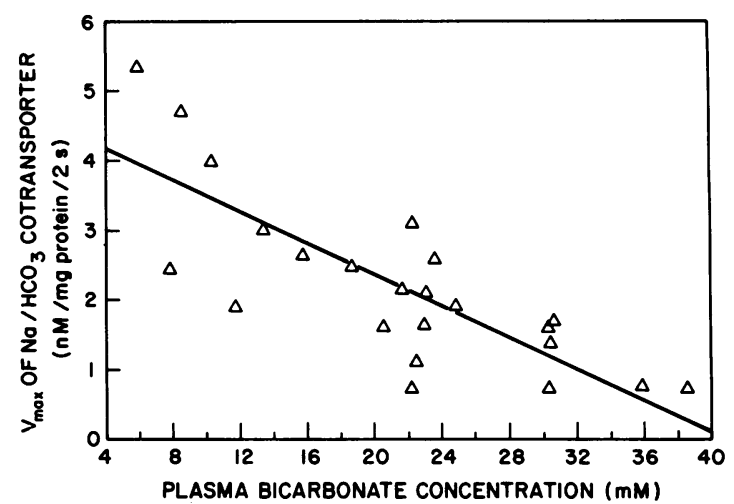

Figure 2. Relationship between blood bicarbonate concentration and maximal rate of $\mathrm{Na}^{+} / \mathrm{HCO}_{3}$ cotransporter. $V_{\max }(\mathrm{nmol} / \mathrm{mg}$ protein $\cdot 2$ s) was determined by Eadie-Hofstee analysis of $\mathrm{Na}^{+} / \mathrm{HCO}_{3}$ cotransport rates in basolateral membrane vesicles. Each data point represents the value obtained from a single membrane preparation in a group of two or three rabbits. Bicarbonate concentration was obtained by arterial blood gas analysis and represents the mean value for rabbits in that group. The $V_{\max }$ were significantly correlated with blood bicarbonate concentration $(r=0.781 ; P<0.001$; d.f., 22$)$, with a linear regression equation (solid line) of $y=-0.11( \pm 0.02) x+4.48( \pm 0.77)$. 


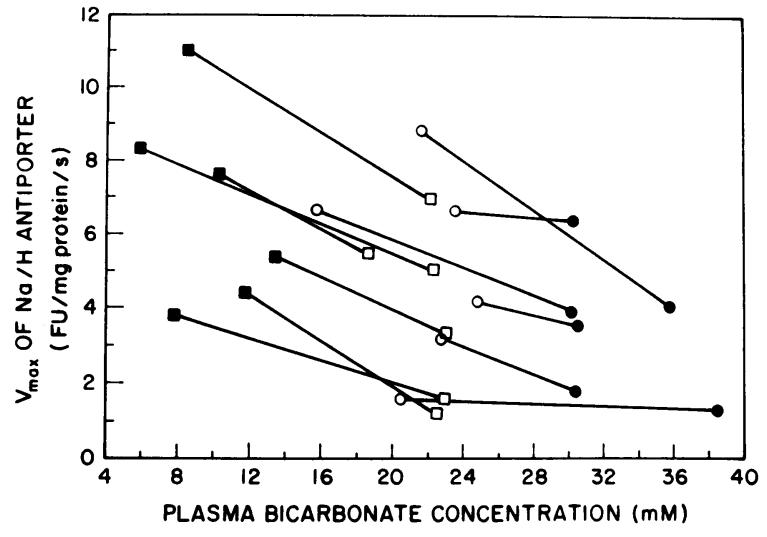

Figure 3. Relationship between blood bicarbonate concentration and maximal rate of $\mathrm{Na}^{+} / \mathrm{HCO}_{3}$ cotransporter. Each data point represents the value obtained from a single membrane preparation in a group of two or three rabbits in the acidosis series (squares) and in the alkalosis series (circles). Control studies (open symbols) are connected to the paired experimental group (closed symbols).

for both the $\mathrm{Na}^{+} / \mathrm{H}^{+}$antiporter and $\mathrm{Na}^{+} / \mathrm{HCO}_{3}$ cotransporter in alkalosis (circles) and acidosis (squares). The solid lines connect each experimental point with the concurrent control point. Two important points emerge from this figure. (a) There was a concordance between the maximal rates for both transport systems, and $(b)$ there was a striking parallelism in the adaptive changes in $V_{\max }$ for both transport systems in response to acidosis (closed squares) and alkalosis (closed circles). The regression line for all of the data points (dashed line) is also included in Fig. 5 $(y=0.31[ \pm 0.08] x+0.66[ \pm 0.94])$. This regression was significant $(P<0.001$; d.f., 22) with an $r$ value of 0.648 .

\section{Discussion}

Technical issues. There are at least four distinct $\mathrm{H}^{+} / \mathrm{HCO}_{3}$ transport mechanisms in the apical and basolateral membranes of the proximal tubule. The $\mathrm{Na}^{+} / \mathrm{H}^{+}$antiporter and $\mathrm{Na}^{+} / \mathrm{HCO}_{3}$ cotransporter are the major systems and were the focus of the

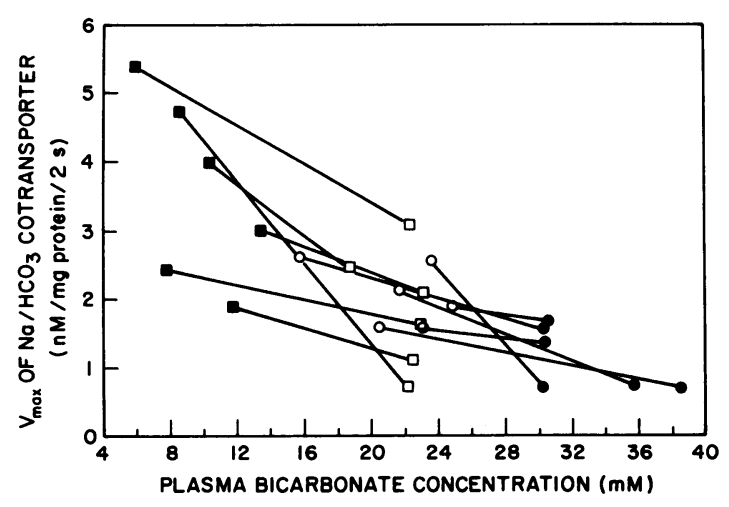

Figure 4. Relationship between blood bicarbonate concentration and maximal rate of $\mathrm{Na}^{+} / \mathrm{H}^{+}$antiporter. Each data point represents the value obtained from a single membrane preparation in a group of two or three rabbits in the acidosis series (squares) and in the alkalosis series (circles). Control studies (open symbols) are connected to the paired experimental group (closed symbols).

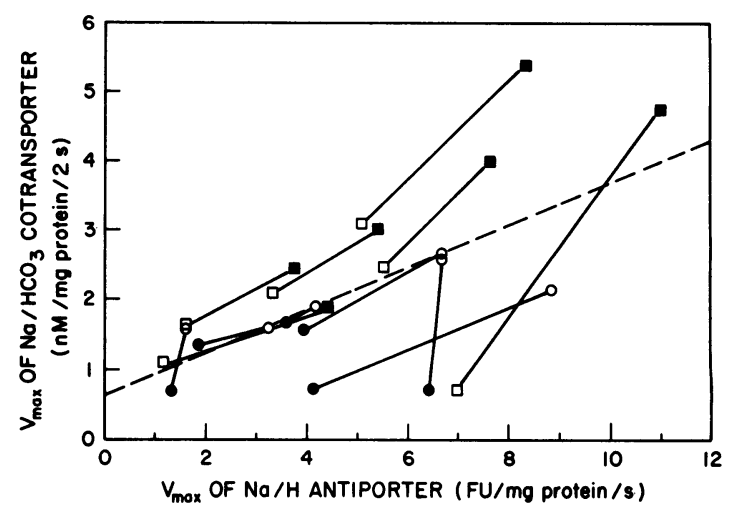

Figure 5. Relationship between maximal rate of the $\mathrm{Na}^{+} / \mathrm{HCO}_{3}$ cotransporter and that of the $\mathrm{Na}^{+} / \mathrm{H}^{+}$antiporter. Each data point represents the value obtained from a single membrane preparation in a group of two or three rabbits in the acidosis series (squares) and in the alkalosis series (circles). Control studies (open symbols) are connected to the paired experimental group (closed symbols). Regression line for all of the data points is shown as a dashed line $(y=0.31[ \pm 0.08] x$ $+0.66[ \pm 0.94])$. This regression was significant $(P<0.001$; d.f., 22$)$ with an $r$ value of 0.648 .

present studies. It is difficult to quantitate the separate contributions of $\mathrm{Na}^{+} / \mathrm{HCO}_{3}$ cotransport and $\mathrm{HCO}_{3} / \mathrm{Cl}^{-}$exchange to bicarbonate exit across the basolateral membrane, so we only measured the rate of $\mathrm{Na}^{+} / \mathrm{HCO}_{3}$ cotransport in the absence of any chloride ions. Recent studies have reported that the $\mathrm{Na}^{+}$/ $\mathrm{HCO}_{3}$ cotransporter can be demonstrated in the complete absence of chloride $(9,10)$. This approach does not preclude the possibility that the $\mathrm{HCO}_{3} / \mathrm{Cl}^{-}$exchanger might also be regulated by metabolic acidosis or alkalosis, even though this transport system is thought to play a relatively minor role in bicarbonate exit across the basolateral membrane (35). At present, the contribution of an apical membrane $\mathrm{H}^{+}$-ATPase to bicarbonate reabsorption in the proximal tubule is not well defined $(20,36)$, so this transport system was not examined in the present studies.

The present experiments utilized sucrose density gradients (29) for the simultaneous preparation of brush border and apical membranes from the same kidneys. Although this advantage was considered crucial for the present experimental design, it must be pointed out that the resulting brush border membrane vesicles do not have the same degree of enrichment as is obtained with the standard magnesium aggregation method in this laboratory $(2,33)$ because the sucrose density preparation has been optimized for the preparation of basolateral membrane vesicles (29). Furthermore, the absolutes rates of $\mathrm{Na}^{+} / \mathrm{H}^{+}$antiporter activity compare very well with previous determinations in control and metabolic acidosis (2), lending further support to the adequacy of the membrane preparations for the present studies.

Another point relates to the assessment of the acid-base status of the animals. We have previously observed that the measurement of arterial $\mathrm{pH}$ at the time of sacrifice may underestimate the severity of metabolic acidosis, presumably because of acute hyperventilation. In a previous study, we used plasma total $\mathrm{CO}_{2}$ contents as measured by microcalorimetry (2). In the present study, we used arterial blood gas determinations, but found that the blood bicarbonate concentration was the most appropriate variable for estimating the acid-base status because any shortterm effects of hyperventilation at the time of sampling would be minimized. 
Experimental models for metabolic acidosis and alkalosis were chosen to represent more than an acute change in acidbase status (Table I). At least three animals were treated in each group, and arterial blood gas determinations were done on the morning of sacrifice and membrane preparation. Two or three animals were used for the membrane preparations, the choice being based upon the measured blood bicarbonate concentrations. Thus, the animals were selected before sacrifice to most nearly represent the desired acid-base condition. In addition, two or three control rabbits were simultaneously sacrificed with their experimental group so as to minimize spontaneous variations in the membrane transport rates. Our previous studies have demonstrated the absolute necessity of such a paired design (2). The open (control) symbols in Figs. 3 and 4 show the fairly wide variability in transport rates even though the acid-base status of the control animals was carefully defined. While it is obvious that there may be factors other than acid-base status that account for variation in basal transport rates, the present studies used contemporaneous controls in an effort to minimize intraanimal variability. Whereas both acidosis and alkalosis were associated with mild volume depletion (judging from the increased blood urea nitrogen levels), the volume status was similar in both sets of controls so this factor may not necessarily explain the variability observed in the control groups.

A final technical point pertains to the determination of maximal rates of transport. At least five sodium concentrations were used in each assay, and each was assayed in quadruplicate so that $V_{\max }$ and $K_{\mathrm{m}}$ values could be compared between groups. While it would be desirable to compare the rates of $\mathrm{H}^{+}$secretion across the apical membrane to the rate of bicarbonate exit across the basolateral membrane, such a comparison would be premature in our view. Maximal rates of transport are determined under different experimental conditions for each transport system. The actual rates of transport in vitro may well be affected by the intracellular $\mathrm{pH}$, buffering, divalent cations, etc. Furthermore, it is not certain that the amiloride-sensitive $\mathrm{Na}^{+} / \mathrm{H}^{+}$ antiporter is the only means by which $\mathrm{H}^{+}$is secreted across the apical membrane $(20,36)$. For these reasons, even though it is possible to convert the observed rates of $\mathrm{Na}^{+} / \mathrm{H}^{+}$exchange (FU/ $\mathrm{mg}$ protein $\cdot \mathrm{s}$ ) to flux rates (37), separate units have been maintained for the $\mathrm{Na}^{+} / \mathrm{H}^{+}$antiporter and $\mathrm{Na}^{+} / \mathrm{HCO}_{3}$ cotransporter, and quantitative comparisons of the two separate transport systems have not been made.

Parallel adaptation of $\mathrm{H}^{+} / \mathrm{HCO}_{3}$ transporters. The present experiments demonstrate that $V_{\max }$ values of $\mathrm{Na}^{+} / \mathrm{H}^{+}$antiporter and $\mathrm{Na}^{+} / \mathrm{HCO}_{3}$ cotransporter are regulated in a parallel fashion (Fig. 5). Both systems vary inversely with the blood bicarbonate concentration (Figs. 1 and 2). $V_{\max }$ of the $\mathrm{Na}^{+} / \mathrm{H}^{+}$antiporter and $\mathrm{Na}^{+} / \mathrm{HCO}_{3}$ cotransporter increased in metabolic acidosis and decreased in metabolic alkalosis, without any change in the $K_{\mathrm{m}}$ values of either system (Table III). The comparison in Fig. 5 emphasizes the parallel changes that occurred in each system. Furthermore, the fact that the control points (open symbols) are distributed along the regression indicates that there is a strong concordance of the maximal transport rates for both systems in vivo.

Most of the filtered load of $\mathrm{HCO}_{3}$ is reabsorbed in the proximal tubule (20). The rate of proximal tubular bicarbonate reabsorption shows strong dependence on the filtered load of bicarbonate $(22,38,39)$. In chronic metabolic acidosis induced by ammonium chloride, the absolute rate of total $\mathrm{CO}_{2}$ absorption in the proximal tubule is reduced when compared with control hydropenic conditions (40). When compared at comparable luminal total $\mathrm{CO}_{2}$ concentrations and tubular fluid flow rates, however, the rate of total $\mathrm{CO}_{2}$ absorption is significantly increased in the acidotic state (23). Therefore, whereas the increased $V_{\max }$ of the $\mathrm{Na}^{+} / \mathrm{H}^{+}$antiporter in acidosis (1) would increase proximal bicarbonate reabsorption, the absolute rate of reabsorption appears to be limited in vivo by the reduction in bicarbonate concentration of the glomerular filtrate $(23,40)$. Even though the absolute rate of bicarbonate reabsorption is reduced in vivo in metabolic acidosis, it appears that the adaptation of the $V_{\max }$ of the $\mathrm{Na}^{+} / \mathrm{H}^{+}$antiporter is of physiologic importance. The data in Fig. 1 confirm our previous finding that the degree of adaption of $V_{\max }$ is directly related to the severity of induced metabolic acidosis. The direct implication of this finding is that the renal responses to perturbations in systemic $\mathrm{pH}$ and/or bicarbonate concentration are of regulatory importance, in contrast to previous interpretations (41).

Bicarbonate absorption by proximal renal tubules is considered to be mediated by $\mathrm{Na}^{+} / \mathrm{H}^{+}$exchange and perhaps $\mathrm{H}^{+}$-dependent ATPase in the apical membranes $(20,36)$, and $\mathrm{Na}^{+}$/ $\mathrm{HCO}_{3}$ cotransport $(9-19)$ and $\mathrm{HCO}_{3} / \mathrm{Cl}^{-}$exchange $(35,42)$ in the basolateral membrane. Of these transporters, the $\mathrm{Na}^{+} / \mathrm{H}^{+}$ antiporter in the brush border membrane and $\mathrm{Na}^{+} / \mathrm{HCO}_{3} \mathrm{co}-$ transporter in the basolateral membrane are considered to play major roles in regulating the intracellular $\mathrm{pH}$ of proximal tubular cells (17). Our present finding, that there is parallel adaptation of the $\mathrm{Na}^{+} / \mathrm{H}^{+}$antiporter and the $\mathrm{Na}^{+} / \mathrm{HCO}_{3}$ cotransporter in acid-base perturbations, suggests that changes in intracellular $\mathrm{pH}$ are minimized during systemic acid-base perturbations as a result of this dual regulation. Alpern and Chambers (17) recently demonstrated that the effect on intracellular $\mathrm{pH}$ of basolateral $\mathrm{Na}^{+} / \mathrm{HCO}_{3}$ exceeds that of the apical membrane $\mathrm{Na}^{+} / \mathrm{H}^{+}$antiporter during short-term changes in the $\mathrm{pH}$ of luminal and peritubular perfusion solutions in studies of the in vivo microperfused rat proximal convoluted tubule. Whether this same relative importance pertains to the subacute acid-base changes examined in the present studies is a question that warrants direct investigation.

Cohn et al. (1) observed that $\mathrm{Na}^{+} / \mathrm{H}^{+}$exchange activity was increased in brush border vesicles prepared from acidotic dogs. Tsai et al. (2) observed that the $V_{\max }$ of $\mathrm{Na}^{+} / \mathrm{H}^{+}$antiporter increased in renal cortical brush border membrane vesicles prepared from rabbits with metabolic acidosis. This finding was also observed in rats by Kinsella et al. (2). We confirmed these findings in the present study, and have observed that $V_{\max }$ of the $\mathrm{Na}^{+} / \mathrm{HCO}_{3}$ cotransporter in basolateral membrane vesicles is also increased in metabolic acidosis. Such parallel regulation may be a mechanism to maintain acid-base homeostasis of the animal, with maintenance of intracellular $\mathrm{pH}$ in a relatively narrow range. Another possibility is that cell $\mathrm{pH}$ falls during metabolic acidosis and this in turn stimulates the activity of the apical membrane $\mathrm{Na}^{+} / \mathrm{H}^{+}$antiporter (28). Concurrent activation of the basolateral bicarbonate exit step would maintain the relatively acidic cell $\mathrm{pH}$ and thereby maintain the stimulation of the apical $\mathrm{H}^{+}$secretory system(s) in metabolic acidosis. Alternatively, the increased $V_{\max }$ of the $\mathrm{Na}^{+} / \mathrm{HCO}_{3}$ cotransporter may be a primary event in metabolic acidosis, decreasing the cell bicarbonate and $\mathrm{pH}$, and thereby activating the $\mathrm{Na}^{+} / \mathrm{H}^{+}$antiporter (28) so that cell $\mathrm{pH}$ becomes less acidic. This sequence of events is consistent with the measured rates of both transport systems during short-term changes in the luminal and peritubular pH (17). However, the adaption to subacute acid-base pertur- 
bations examined in our studies is not simply a matter of allosteric activation of the transporters, but rather an absolute increase in $V_{\max }$ (either number of carriers or increased turnover of each carrier) which persists when the membranes are isolated and studied in vitro under defined conditions ("memory effect"). Whatever the teleologic reason for the parallel regulation of both transport systems during acid-base disturbances, it seems likely that the combined effect would maintain cell $\mathrm{pH}$ within a relatively narrow, albeit acidotic range. At the expense of continued intracellular acidosis, the secretion of $\mathrm{H}^{+}$into the lumen, and bicarbonate reabsorption would be maximized. An implication of this hypothesis is that the response of the proximal tubule to metabolic acidosis would defend systemic pH by enhancing proximal proton secretion and bicarbonate reabsorption despite continued intracellular acidosis.

In contrast to metabolic acidosis, regulation of bicarbonate absorption in proximal tubules of alkalotic animals is somewhat controversial. Reduced glomerular filtration is responsible, at least acutely, for maintaining the alkalotic state in Munich-Wistar rats (43). In longer term studies, increased bicarbonate absorption by the renal proximal tubule was observed even when glomerular filtration rate was restored to normal (38). This increase was accounted for by chronic adaptive hypertrophy of the proximal tubule and a load-dependent response indistinguishable from that seen in normal rats (38). Recently Liu and Cogan (39) found that bicarbonate rebsorption in the late proximal convoluted tubule was flow dependent but also inhibited by alkalemia and chronic metabolic alkalosis (24). This inhibition of bicarbonate absorption was attributed to impaired bicarbonate exit from the cell $(24,38)$. Our results (Fig. 2 and Table I) suggest that activity of the bicarbonate exit step is decreased during metabolic alkalosis because of a decrease in the maximal activity of the $\mathrm{Na}^{+}$/ $\mathrm{HCO}_{3}$ cotransporter.

Suspended proximal tubular cells from rabbits with metabolic alkalosis showed a decrease in amiloride-sensitive, sodium-dependent intracellular alkalinization compared to normal controls (4). The present studies used a similar metabolic alkalosis protocol, as did Blumenthal et al. (4), and demonstrated that $\mathrm{Na}^{+}$/ $\mathrm{HCO}_{3}$ cotransport activity was suppressed in metabolic alkalosis. The model utilized is diuretic-induced, $\mathrm{Cl}^{-}$-deficiency alkalosis with attendant hypokalemia. The fact that $\mathrm{Na}^{+} / \mathrm{H}^{+}$antiporter activity was not significantly reduced in this model of hypokalemic, hypochloremic metabolic alkalosis may be the result of hypokalemia, which has been shown to increase the activity of the $\mathrm{Na}^{+} / \mathrm{H}^{+}$antiporter (8). Even though reduction in $V_{\max }$ of the $\mathrm{Na}^{+} / \mathrm{H}^{+}$antiporter was not statistically significant by paired $t$ test (Table III), it should be pointed out that $V_{\max }$ decreased in each of the six experiments, but the control rates of $\mathrm{Na}^{+} / \mathrm{H}^{+}$ antiporter activity were quite variable (Fig. 4).

In summary, maximal transport rates of the $\mathrm{Na}^{+} / \mathrm{H}^{+}$antiporter and the $\mathrm{Na}^{+} / \mathrm{HCO}_{3}$ cotransporter are inversely related with the plasma bicarbonate concentration from 6 to $39 \mathrm{mM}$. Furthermore, the maximal transport rates of both systems varied in parallel; when $V_{\max }$ for the $\mathrm{Na}^{+} / \mathrm{HCO}_{3}$ cotransporter was plotted against $V_{\max }$ for the $\mathrm{Na}^{+} / \mathrm{H}^{+}$antiporter for each of the 24 groups of rabbits, the regression coefficient $(r)$ was 0.648 ( $P$ $<0.001)$. There was, no effect of acidosis or alkalosis on the affinity for $\mathrm{Na}^{+}$of either transporter. We conclude that both apical and basolateral $\mathrm{H}^{+} / \mathrm{HCO}_{3}$ transporters adapt during acidbase disturbances, and that the maximal transport rates of both systems vary in parallel. These parallel changes would maintain the intracellular $\mathrm{pH}$ in a relatively narrow range during chronic changes in the extracellular $\mathrm{pH}$ and could represent an adaptive response of the proximal tubule that would tend to correct the chronic acid-base disturbance.

\section{Acknowledgments}

This project was supported by the Veterans Administration Research Service and National Institutes of Health grant AM-19407 (Dr. Warnock). Dr. Akiba and Dr. Rocco were post-doctoral fellows in the Cardiovascular Research Institute during these studies. Dr. Akiba was supported in part by a stipend from the National Kidney Foundation. Dr. Rocco was supported by National Institutes of Health Training Grant AM-07219.

\section{References}

1. Cohn, D. E., S. Klahr, and M. R. Hammerman. 1983. Metabolic acidosis and parathyroidectomy increase $\mathrm{Na}^{+}-\mathrm{H}^{+}$exchange in brush border vesicles. Am. J. Physiol. 245:F217-F222.

2. Tsai, C.-J., H. E. Ives, R. J. Alpern, V. J. Yee, D. G. Warnock, and F. C. Rector, Jr. 1984. Increased $V_{\max }$ for $\mathrm{Na}^{+} / \mathrm{H}^{+}$antiporter activity in proximal tubule brush border vesicles from rabbits with metabolic acidosis. Am. J. Physiol. 247:F339-F343.

3. Kinsella, J., T. Cudjik, and B. Sacktor. 1984. $\mathrm{Na}^{+} / \mathrm{H}^{+}$exchange in isolated renal brush border membrane vesicles in response to metabolic acidosis: kinetic effects. J. Biol. Chem. 259:13224-13227.

4. Blumenthal, S. S., R. A. Ware, and J. G. Kleinman. 1985. Proximal tubule hydrogen ion transport processes in diuretic-induced metabolic alkalosis. J. Lab. Clin. Med. 106:17-22.

5. Kinsella, J. L., J. M. Freiberg, and B. Sacktor. 1985. Glucocorticoid activation of $\mathrm{Na}^{+} / \mathrm{H}^{+}$exchange in renal brush border vesicles: kinetic effects. Am. J. Physiol. 248:F233-F239.

6. Vigne, P., T. Jean, P. Barbry, C. Frelin, L. G. Fine, and M. Lazdunski. 1985. $\left[{ }^{3} \mathrm{H}\right]$ Ethylpropylamiloride, a ligand to analyze the $\mathrm{Na}^{+} /$ $\mathrm{H}^{+}$exchange system in the membranes of normal and hypertrophied kidneys. J. Biol. Chem. 260:14120-14125.

7. Harris, R. C., J. C. Seifter, and B. M. Brenner. 1984. Adaptation of $\mathrm{Na}^{+} / \mathrm{H}^{+}$exchange in renal microvillus membrane vesicles: role of dietary protein and uninephrectomy. J. Clin. Invest. 74:1979-1987.

8. Seifter, J. L., and R. C. Harris. 1985. Chronic K depletion increases $\mathrm{Na}-\mathrm{H}$ exchange in rat renal cortical brush border membrane vesicles. Kidney Int. 27:384. (Abstr.)

9. Akiba, T., R. J. Alpern, J. Eveloff, J. Calamina, and D. G. Warnock. 1986. Electrogenic sodium/bicarbonate cotransport in rabbit renal cortical basolateral membrane vesicles. J. Clin. Invest. 78:1472-1478.

10. Grassl, S. M., and P. S. Aronson. 1986. Na- $\mathrm{HCO}_{3}$ cotransport in basolateral membrane vesicles isolated from rabbit renal cortex. $J$. Biol. Chem. 261:8778-8783.

11. Boron, W. F., and E. L. Boulpaep. 1983. Intracellular pH regulation in the renal proximal tubule of the salamander: basolateral $\mathrm{HCO}_{3}{ }^{-}$ transport. J. Gen. Physiol. 81:53-94.

12. Burckhardt, B.-Ch., K. Sato, and E. Frömter. 1984. Electrophysiological analysis of bicarbonate permeation across the peritubular cell membrane of rat kidney proximal tubule. I. Basic observations. Pfluegers Arch. Eur. J. Physiol. 401:34-42.

13. Matsushima, Y., B. Cohen, W. B. Guggino, and G. Giebisch. 1984. Electrical effects of potassium and bicarbonate on proximal tubule cells of Necturus. J. Membr. Biol. 79:145-152.

14. Biagi, B. A. 1985. Effect of the anion transport inhibitor, SITS, on the proximal straight tubule of the rabbit perfused in vitro. J. Membr. Biol. 81:25-31.

15. Sasaki, S., T. Shiigai, and J. Takeuchi. 1985. Intracellular pH in the isolated perfused rabbit proximal straight tubule. Am. J. Physiol. 249:F417-F423.

16. Yoshitomi, K., B.-Ch. Burckhardt, and E. Frömter. 1985. Rheogenic sodium-bicarbonate cotransport in the peritubular cell membrane of rat renal proximal tubule. Pfluegers Arch. Eur. J. Physiol. 405:360366. 
17. Alpern, R. J., and M. Chambers. 1986. Cell pH in the rat proximal convoluted tubule: regulation by luminal and peritubular $\mathrm{pH}$ and sodium concentration. J. Clin. Invest. 78:502-510.

18. Alpern, R. J. 1985. Mechanism of basolateral membrane $\mathrm{H}^{+} /$ $\mathrm{OH}^{-} / \mathrm{HCO}_{3}^{-}$transport in the rat proximal convoluted tubule: a sodiumcoupled electrogenic process. J. Gen. Physiol. 86:613-636.

19. Jentsch, T. J., B. S. Schill, P. Schwartz, H. Matthes, S. K. Keller, and M. Wiederholt. 1985. Kidney epithelial cells of monkey origin (BSC1) express a sodium bicarbonate cotransport: characterization by ${ }^{22} \mathrm{Na}^{+}$ flux measurements. J. Biol. Chem. 260:15554-15560.

20. Alpern, R. J., D. G. Warnock, and F. C. Rector, Jr. 1986. Renal acidification mechanisms. In The Kidney. B. M. Brenner and F. C. Rector, Jr., editors. W. B. Saunders \& Co., Philadelphia. 3rd ed. 206-249.

21. Madias, N. E., and S. J. Zelman. 1986. The renal response to chronic mineral acid feeding: a re-examination of the role of systemic pH. Kidney Int. 29:667-674.

22. Cogan, M. G., and R. J. Alpern. 1984. Regulation of proximal bicarbonate reabsorption. Am. J. Physiol. 247:F387-F395.

23. Kunau, R. T., Jr., J. I. Hart, and K. A. Walker. 1985. Effect of metabolic acidosis on proximal tubular total $\mathrm{CO}_{2}$ absorption. Am. J. Physiol. 249:F62-F68.

24. Liu, F.-Y., and M. G. Cogan. 1987. Acidification in the late proximal convoluted tubule is inhibited in chronic metabolic acidosis. Kidney Int. 31:412. (Abstr.)

25. Struyvenberg, A., R. B. Morrison, and A. S. Relman. 1968. Acidbase behavior of separated canine renal tubular cells. Am. J. Physiol. 214:1155-1162.

26. Adam, W. R., A. P. Koretsky, and M. W. Weiner. 1985. Measurement of renal $\mathrm{pH}$ by ${ }^{31} \mathrm{P}-\mathrm{NMR}$ : effect of acidosis and potassium depletion. Kidney Int. 22:277. (Abstr.)

27. Trivedi, B., and R. L. Tannen. 1986. Effect of respiratory acidosis on intracellular pH of the proximal tubule. Am. J. Physiol. 250:F1039F1045.

28. Aronson, P. S., J. Nee, and M. A. Suhm. 1982. Modifier role of internal $\mathrm{H}^{+}$with the $\mathrm{Na}^{+}-\mathrm{H}^{+}$exchanger in renal microvillus membrane vesicles. Nature (Lond.). 299:161-163.

29. Ives, H. E., V. J. Yee, and D. G. Warnock. 1983. Asymmetric distribution of the $\mathrm{Na}^{+} / \mathrm{H}^{+}$antiporter in the renal proximal tubule epithelial cell. J. Biol. Chem. 258:13513-13516.

30. Turner, R. J., and A. Moran. 1982. Heterogeneity of sodium- dependent D-glucose transport sites along the proximal tubule: evidence from vesicle studies. Am. J. Physiol. 242:F406-F414.

31. Schoner, W., C. von Ilberg, R. Krammer, and W. Seubert. 1967. On the mechanism of $\mathrm{Na}^{+}$- and $\mathrm{K}^{+}$-stimulated hydrolysis of adenosine triphosphate. Eur. J. Biochem. 1:334-343.

32. Lowry, O. H., N. J. Rosenbrough, A. L. Fine, and R. J. Randall. 1951. Protein measurement with the Folin phenol reagent. J. Biol. Chem. 193:265-273.

33. Warnock, D. G., W. W. Reenstra, and V. J. Yee. 1982. $\mathrm{Na}^{+} / \mathrm{H}^{+}$ antiporter of brush border vesicles: studies with acridine orange uptake. Am. J. Physiol. 242:F733-F739.

34. Segel, I. H. 1975. Enzyme Kinetics. Wiley and Sons, New York. 360-375.

35. Alpern, R. J., and M. Chambers. 1986. Sodium-dependent $\mathrm{Cl} /$ $\mathrm{HCO}_{3}$ exchange on the basolateral membrane of the rat proximal convoluted tubule. Clin. Res. 34:587a. (Abstr.)

36. Gurich, R. J., and D. G. Warnock. 1986. Electrically neutral $\mathrm{Na}^{+} / \mathrm{H}^{+}$exchange in endosomes obtained from rabbit renal cortex. Am. J. Physiol. 251:F702-F709.

37. Ives, H. E. 1985. Proton/hydroxyl permeability of proximal tubule brush border vesicles. Am. J. Physiol. 248:F78-F86.

38. Maddox, D. A., and F. J. Gennari. 1986. Load dependence of proximal tubular bicarbonate reabsorption in chronic metabolic alkalosis in the rat. J. Clin. Invest. 77:706-716.

39. Liu, F.-L., and M. G. Cogan. 1986. Axial heterogeneity of bicarbonate, chloride and water transport in the rat proximal convoluted tubule. Effect of change in luminal flow rate and alkalemia. J. Clin. Invest. 78:1547-1557.

40. Cogan, M. G., and F. C. Rector, Jr. 1982. Proximal reabsorption during metabolic acidosis in the rat. Am. J. Physiol. 242:F499-F507.

41. Schwartz, W. B., and J. J. Cohen. 1978. The nature of the renal response to chronic disorders of acid-base equilibrium. Am. J. Med. 64: 417-428.

42. Grassl, S. M., L. P. Karniski, and P. S. Aronson. 1985. Cl-HCO exchange in rabbit renal cortical basolateral membrane vesicles. Kidney Int. 27:282. (Abstr.)

43. Cogan, M. G., and F.-Y. Liu. 1983. Metabolic alkalosis in the rat. Evidence that reduced glomerular filtration rather than enhanced tubular bicarbonate reabsorption is responsible for maintaining the alkalotic state. J. Clin. Invest. 71:1141-1160. 